\title{
MiR-378 Promotes the Migration of Liver Cancer Cells by Down-Regulating Fus Expression
}

\author{
Jichun Ma Jiang Lin ${ }^{\mathrm{a}}$ Jun Qian ${ }^{\mathrm{a}}$ Wei Qian ${ }^{\mathrm{a}}$ Jiayu Yin ${ }^{\mathrm{a}}$ Burton Yang ${ }^{\mathrm{b}}$ Qin Tang ${ }^{\mathrm{a}}$ \\ Xingxing Chen ${ }^{\mathrm{a}}$ Xiangmei Wen ${ }^{\mathrm{a}}$ Hong Guo $^{\mathrm{a}}$ Zhaoqun Deng ${ }^{\mathrm{a}}$
}

aAffiliated People's Hospital of Jiangsu University, Zhenjiang, Jiangsu, China; 'bunnybrook Research Institute, Sunnybrook Health Sciences Centre, Toronto, Ontario, Canada

\section{Key Words}

MicroRNA • Liver cancer cell • Migration • Invasion • Metastasis

\begin{abstract}
Background: miR-378 regulates osteoblast differentiation and participates in tumor cell selfrenewal and chemo-resistance. However, the function of miR-378 in liver cancer cell migration has not been reported to date. Methods: miR-378 expression was examined using real-time quantitative PCR. HepG2 cell migration and liver cell invasion were examined using woundhealing and cell invasion assays. Additionally, HepG2 cell metastasis was analyzed in nude mice. Results: miR-378 over-expression enhances HepG2 cell proliferation, migration and liver cell invasion. Typical metastatic lesions were found in the livers of mice injected with miR-378transfected cells, and high levels of the CMV promoter were detected in the nodules, indicating that miR-378 promoted the metastasis of the tumor cells to the liver. We also demonstrated that miR-378 down-regulated Fus expression. Conclusions: Our results suggested that miR378 enhanced cell migration and metastasis by down-regulating Fus expression.
\end{abstract}

Copyright $\odot 2014$ S. Karger AG, Basel

\section{Introduction}

miRNAs are single-stranded RNAs that are 18-24 nucleotides and that are generated by an RNase III-type enzyme from an endogenous transcript containing a local hairpin structure $[1,2]$. miRNAs pair with the messages of protein-coding genes to direct posttranscriptional repression [3] and target mRNAs based on sequence complementarity

J. Ma and J. Lin contributed equally.

Prof. Zhaoqun Deng

Affiliated People's Hospital of Jiangsu University,8 Dianli Road, 212002 Zhenjiang, (People's Republic of China)

Tel. +86 511 88915586, Fax +86 511 85234387, E-Mail dengqian2012@gmail.com 
with target $3^{\prime}$-untranslated regions (3'-UTRs), leading to translational repression and/ or to mRNA cleavage [4]. miRNAs are involved in cell differentiation [5], apoptosis [6], cell proliferation [7, 8], division [9], protein secretion [10], immune regulation [11], viral infection [12], cancer development [13, 14], invasion [15, 16], tissue morphogenesis and growth $[17,18]$, angiogenesis $[19,20]$ and metastasis [21]. The largest functional group of miRNAs are those miRNAs involved in cancer development, and among these, some have been reported to function as oncogenic miRNAs or tumor suppressors, whereas others exert diverse functions [22].

Many miRNAs, including miR-206, miR-17, miR-15, miR-124, and miR-29 [23, 24], are down-regulated in various cancers and have the potential to act as tumor suppressors. Additionally, some miRNAs, such as miR-378, are over-expressed in diverse cancers and seem to function as oncogenes [15, 25-28]. Previous studies have indicated that miR-378 can promote cell survival, tumor growth, and angiogenesis in glioblastoma cells [26]. miR378 regulates osteoblast differentiation [28] and participates in tumor cell self-renewal and chemo-resistance [27]. However, the function of miR-378 in liver cancer cell migration has not been reported thus far. The Fus-1 protein is a tumor suppressor that has been established as a mitochondrial tumor suppressor, immunomodulator, and antioxidant protein. The loss of Fus1 results in an autoimmune-like syndrome with chronic inflammation and the spontaneous formation of both vascular tumors and lymphomas. Recent studies have shown that Fus-1 plays important roles in carcinogenesis [29]. The Fus-1 3' UTR includes a potential target sequence of miR-378 in nucleotides 748-770. Fus- 1 is reported to function as a tumor suppressor gene and is located on human chromosome 3p21.3. Fus-1 can significantly inhibit tumor cell growth in vitro and in vivo. We report that stable expression of miR-378 plays a role in tumor growth and migration by down-regulating Fus.

\section{Materials and Methods}

\section{Cell lines and transfection}

Human liver cancer cells (HepG2) were cultured in Dulbecco's modified Eagle's medium (DMEM, Gibco) supplemented with 10\% fetal bovine serum (FBS, Gibco) and $100 \mathrm{U} / \mathrm{ml}$ penicillin/streptomycin in an incubator with $5 \% \mathrm{CO}_{2}$ at $37^{\circ} \mathrm{C}$. The cells were studied while in the exponential growth phase. HepG2 cells $\left(3 \times 10^{5}\right.$ per well) were transfected in 6-well plates with Lipofectamine 2000 (Invitrogen) according to the manufacturer's instructions. The cells were transfected with $3 \mu \mathrm{g}$ of the miR-378 plasmid, anti-378 plasmid, or GFP plasmid control [26]. Then, stably transfected cells were selected using G418 (Gibco) and cell sorting (BD Company). After selection, the transfected cells were harvested, and miR-378 expression was detected by RQ-PCR.

\section{Cell proliferation assays}

miR-378-, anti-miR-378- and GFP-transfected cells were seeded in 96-well tissue culture plates at $3 \times 10^{3}$ cells per well. Cell proliferation was determined using the 3-(4,5-dimethylthiazol-2-yl)-2,5diphenyltetrazolium bromide (MTT) assay (BBI). miR-378-, anti-miR-378- and GFP-transfected cells were grown in 96-well cell culture plates in 10\% FBS medium, and then the medium was replaced with $20 \mu \mathrm{l}$ of MTT reagent ( $5 \mathrm{mg} / \mathrm{ml}$ ) and incubated in $5 \% \mathrm{CO}_{2}$ at $37^{\circ} \mathrm{C}$ for 0.5 and $4 \mathrm{~h}$. Then, the medium was aspirated, and $100 \mu \mathrm{l}$ of dimethyl sulfoxide (DMSO, Sigma-Aldrich) was added to each well. The optical density was measured using a microplate reader.

\section{Wound-healing assay}

Cells were plated at $3 \times 10^{5} /$ dish in 6 -well tissue culture plates. After the cells reached confluence, a plastic pipette tip was drawn across the center of the plates to produce clean 1-mm-wide wound lines. Cell movement into the wound area was examined and photographed at different time points ( 3 and $24 \mathrm{~h}$ ) under a microscope. The distance between the leading edge of the migrating cells and the edge of the wound was measured to estimate cell mobility. 


\section{Cell invasion assay}

The cell invasion assay was performed as described previously [30]. Briefly, cells were seeded into 8- $\mu \mathrm{m}$ cell culture inserts and placed in 24-well cell culture plates. The upper chamber was coated with 100 $\mu \mathrm{l}$ of diluted Matrigel $(1 \mathrm{mg} / \mathrm{ml}$ ). The lower chamber was filled with $600 \mu \mathrm{l}$ of $10 \%$ FBS-DMEM medium. Cells $\left(1 \times 10^{5}\right)$ in $100 \mu \mathrm{l}$ of serum-free DMEM medium were gently loaded onto each filter insert (upper chamber) and then incubated at $37^{\circ} \mathrm{C}$ for $24 \mathrm{~h}$. The filter inserts were removed from the chambers, fixed with methanol for $5 \mathrm{~min}$ and stained with Harris' hematoxylin for $20 \mathrm{~min}$. The samples were subsequently washed, dried and mounted onto slides. The invasive cells were stained blue, visualized under an inverted microscope and then counted in six random fields for statistical analysis.

\section{Flow cytometry}

In total, $5 \times 10^{5}$ cells were scraped with cell scrapers and washed twice with FACS solution (PBS containing $2 \% \mathrm{FBS}$ and $0.1 \% \mathrm{NaN}_{3}$ ). The cells were fixed with $4 \%$ paraformaldehyde for $30 \mathrm{~min}$, permeabilized with $0.1 \%$ Triton X-100 for $15 \mathrm{~min}$, and then washed twice with FACS solution. The cells were incubated with a rabbit monoclonal antibody against the Fus protein (Sigma-Aldrich) at $60 \mu \mathrm{g} / \mathrm{ml}$ for 30 min on ice, then washed twice with FACS solution and incubated with goat anti-rabbit IgG-DyLight 647 (Jackson) at a dilution of 1:100 for 30 min on ice in the dark. After washing twice with FACS solution, Fus expression on the cells was analyzed by flow cytometry.

\section{Metastasis in nude mice}

The miR-378-, anti-miR-378-, and GFP-transfected HepG2 cells were cultured in 10\% FBS-DMEM at $37^{\circ} \mathrm{C}$ with $5 \% \mathrm{CO}_{2}$ to sub-confluence. The medium was replaced with fresh $10 \%$ FBS-DMEM $24 \mathrm{~h}$ before the cells were harvested for injection into the mice. The transfected cells $\left(5 \times 10^{5}\right.$ cells in $\left.200 \mu \mathrm{DMEM}\right)$ were intraperitoneally injected into five-week-old BALB/C nude mice. The mice were grouped at random, with 5 mice in each group. All mice were sacrificed four weeks after injection. At necroscopy, the lungs and livers were dissected carefully and frozen in $-80^{\circ} \mathrm{C}$ for subsequent analysis.

To analyze metastasis, the mouse lung and liver tissues were homogenized, and the genomic DNAs were isolated using a Gentra Puregene Kit (Qiagen) according to the manufacturer's instructions. The tumor burden for each individual tissue was measured using real-time quantitative PCR (RQ-PCR). The primers used were as follows: CMV forward ( $5^{\prime}$-gtc atc gct att acc atg gtg atg cgg- $\left.3^{\prime}\right)$ and CMV reverse (5'-agc tct gct tat ata gac ctc cca ccg- $\left.3^{\prime}\right)$ for genotyping; $\beta$-actin forward $\left(5^{\prime}\right.$-ccg gca tgt gca aag ccg gct tcg- $\left.3^{\prime}\right)$ and $\beta$-actin reverse ( $5^{\prime}$-ctc att gta gaa ggt gtg $\left.\mathrm{cc}-3^{\prime}\right)$ for the loading control.

\section{Western blot analysis}

Cell lysates were prepared from HepG2 cells expressing different constructs and subjected to SDSPAGE electrophoresis on a $12 \%$ separating gel with a $4 \%$ stacking gel section. The lysis buffer contained protease inhibitors (50 mM Tris, $150 \mathrm{mM} \mathrm{NaCl}, 1 \%$ Triton X-100, 1\% sodium deoxycholate, $0.1 \%$ SDS, and $1 \times$ protease inhibitor cocktail). The SDS-PAGE-separated proteins were transferred onto a nitrocellulose membrane (Bio-Rad) in Tris-glycine buffer containing 20\% methanol. Then, the membrane was blocked in PBST containing 3\% BSA for $2 \mathrm{~h}$ at room temperature with gentle shaking. Next, the membrane was incubated at $4^{\circ} \mathrm{C}$ overnight with primary antibody. The next day, the membrane was washed with PBST ( $\left.4 \times 15 \mathrm{~min}\right)$ and incubated at room temperature with secondary anti-rabbit antibody conjugated to horseradish peroxidase in PBST. After washing as described above, the bound antibodies were visualized using a Chemiluminescent HRP Antibody Detection Kit (GE Healthcare Life Sciences).

\section{Real-time quantitative PCR (RQ-PCR)}

Total RNA was extracted from $1 \times 10^{6}$ cells using a mirVana miRNA Isolation Kit (Ambion) according to the manufacturer's instructions, followed by reverse transcription to synthesize cDNA using $1 \mu \mathrm{g}$ of RNA. This PCR reaction was performed using a QuantiMir RT Kit with $1 \mu \mathrm{l}$ of cDNA as a template (Qiagen, miScript Reverse Transcription Kit, cat\#218060; miScript Primer Assay, cat\#218411; miScript SYBR Green PCR Kit, cat\#218073). The mature miR-378-specific primers were purchased from Qiagen. The primers used as realtime PCR controls were human-U6RNAf and human-U6RNAr. The primer sequences for the controls were as follows: human-U6RNAf ( $5^{\prime}$-gtg ctc get tcg gca gca cata tac- $\left.3^{\prime}\right)$ and human-U6RNAr $\left(5^{\prime}\right.$-aaa aat atg gaa cgc ttc acg aat ttg- $\left.3^{\prime}\right)$. 
A

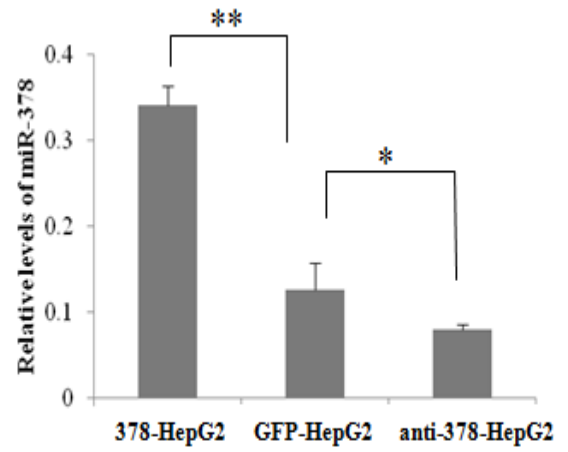

B

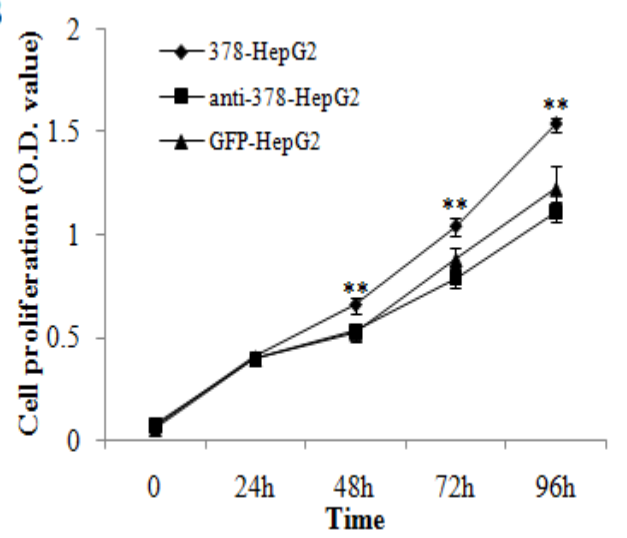

Fig. 1. miR-378 increased the proliferative activity of miR-378 over-expressing cells. (A) RQ-PCR analysis of miR-378 expression. Increased miR-378 expression was observed in miR-378-HepG2 cells $(* *, p<0.01)$ and decreased miR-378 expression was observed in anti-378-HepG2 cells $(*, p<0.05)$ compared with GFPHepG2 cells. (B) miR-378 expression increased the proliferative activity of HepG2 cells.

Statistical analysis

The mean \pm SD values for each group were calculated, and the differences between the groups were assessed using Student's t-test. The values were considered significant when $p<0.05$. All experiments were repeated at least three times.

\section{Results}

miR-378 promoted liver cancer cell proliferation

We transfected miR-378, anti-miR-378 or GFP vector into HepG2 cells and selected transfected cells using neomycin and cell sorting. We observed the effect of transfection by fluorescence microscopy and detected miR-378 expression by RQ-PCR. Increased miR-378 expression in miR-378-HepG2 cells and decreased miR-378 expression in anti-378-HepG2 cells were observed by RQ-PCR (Fig. 1A).

To study the role of miR-378 in regulating cell growth, the miR-378-, anti-miR-378- and GFP-transfected HepG2 cells were subjected to proliferation assays. Cell proliferation was determined by the MTT assay after cell inoculation. The result showed that miR-378-HepG2 cells proliferated faster than GFP-HepG2 cells and the anti-378-HepG2 cells (Fig. 1B). These experiments revealed that miR-378 expression promoted HepG2 cell proliferation.

\section{miR-378 expression enhances liver cancer cell migration}

Wound healing experiments were performed to define the functions of miR-378 in liver cancer cell migration. The miR-378-, anti-miR-378- and GFP-transfected HepG2 cells were maintained in $10 \%$ serum media at equal cell densities overnight. The next day, subconfluent monolayers were wounded linearly by scraping with P100 pipette tips, washed to remove cell debris and refilled with fresh $5 \%$ serum media. The result showed that the miR378-transfected cells promoted HepG2 cell migration more than the GFP-transfected cells in 5\% serum media (Fig. 2), suggesting that miR-378 enhanced the migration of the HepG2 cells to the wounded area.

Effect of miR-378 on liver cancer cell invasion

We found that miR-378 expression affects tumor migration. We further tested the effect of miR-378 on liver cancer cell invasion. The miR-378, anti-miR-378- or GFP-transfected 


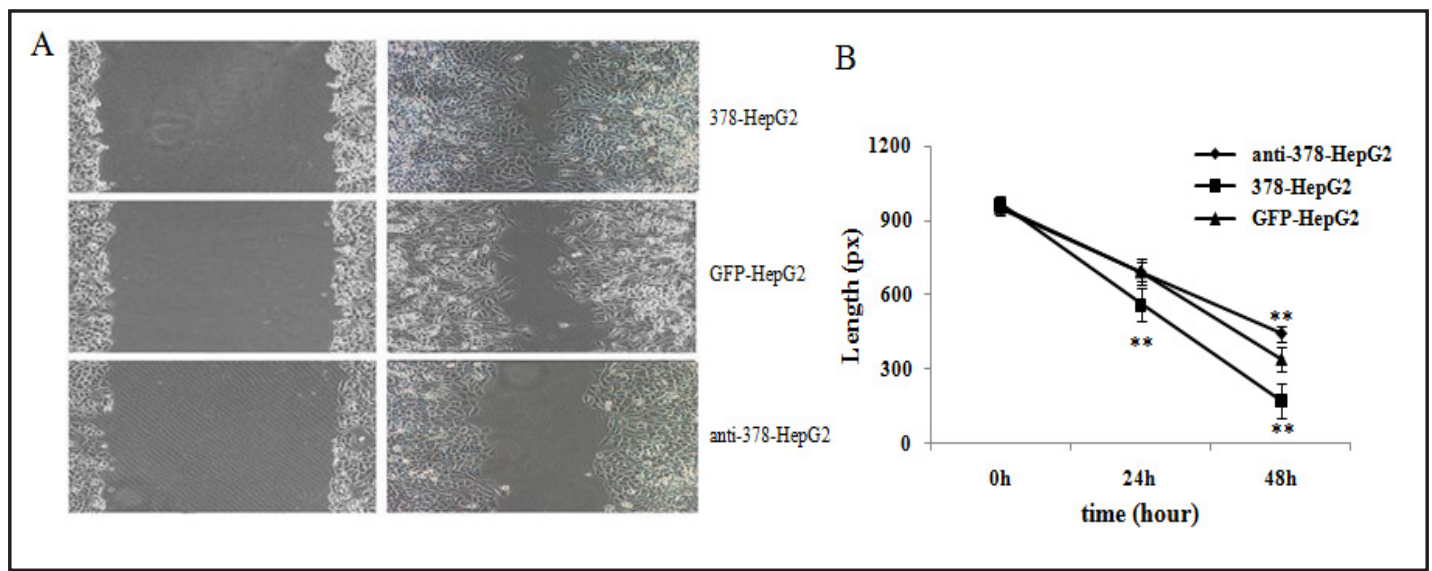

Fig. 2.The role of miR-378 in cell migration. The miR-378-, anti-miR-378- and GFP-transfected HepG2 cells were linearly wounded by scraping with P100 pipette tips and refilled with fresh 5\% serum media. (A) Photographs were taken and the wounds were measured every day. The results showed that the miR-378-transfected cells promoted HepG2 cell migration more than the GFP-transfected cells. (B) Wound measurement. **, $p<0.01$ compared with GFP-HepG2 cells.

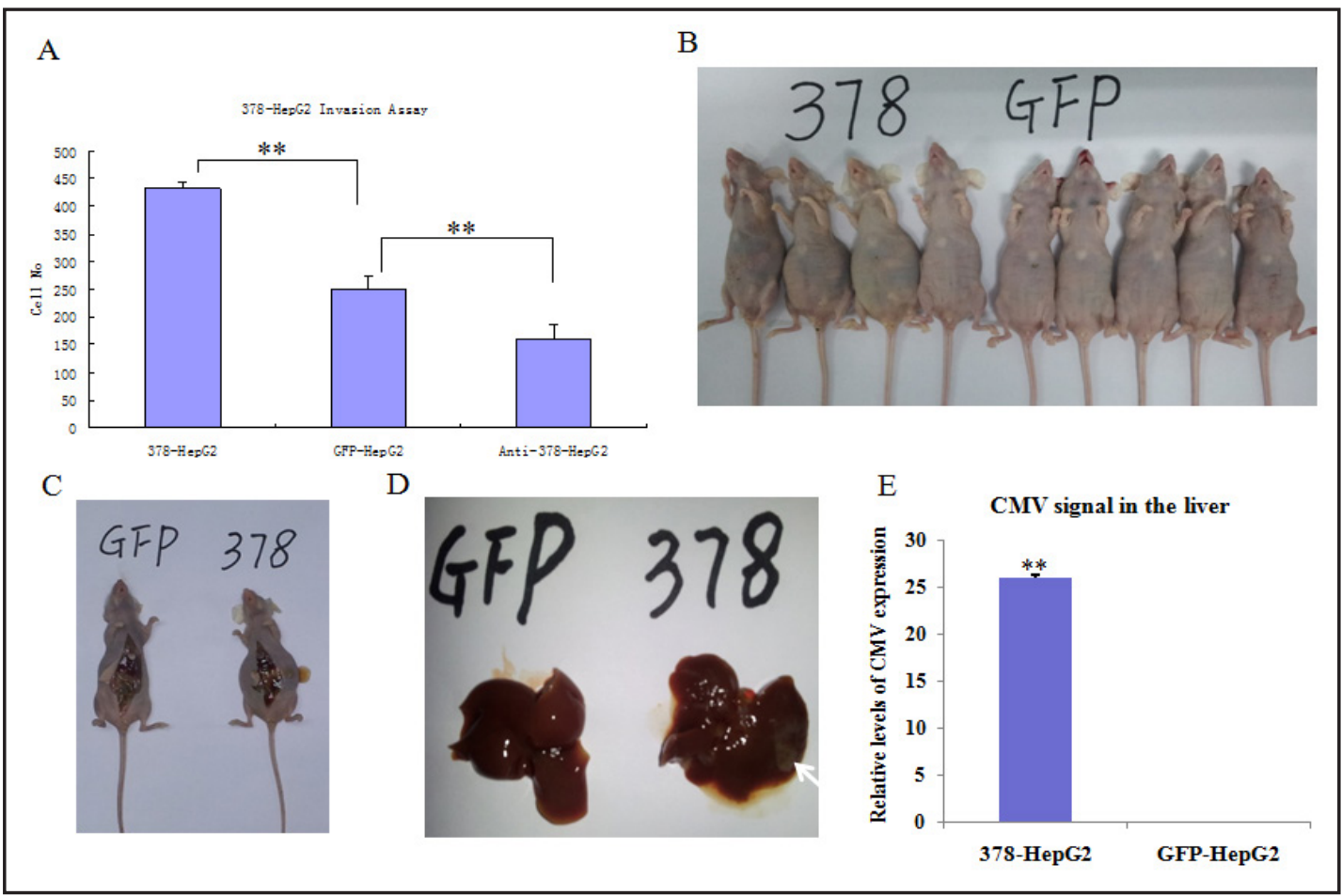

Fig. 3. miR-378 affected liver cancer cell invasion and enhanced liver cancer metastasis in a mouse model. (A) The miR-378-, anti-miR-378- and GFP-transfected HepG2 cells were inoculated on Matrigel in inserts and the invasion was measured. A greater number of miR-378-transfected HepG2 cells than GFP-transfected HepG2 cells invaded into the Matrigel. **, $p<0.01$ compared with GFP-HepG2 cells. (B, C) The miR-378- or GFP-transfected HepG2 cells were intraperitoneally injected into BALB/c nude mice. The mice were sacrificed and examined at 4 weeks after the injection. Four mice in the miR-378 group generated more ascitic fluid than the mice in the GFP-HepG2 group. (D) Typical metastatic lesion (white arrow) found in the livers of mice in the miR-378 group. (E) DNA was isolated from liver tissues and subjected to PCR to amplify the CMV promoter to indicate the metastasis of the tissue.

HepG2 cells were inoculated on Matrigel in inserts, and the cells that invaded through the inserts were examined. miR-378 expression enhanced cell invasion compared with the GFP- 
A

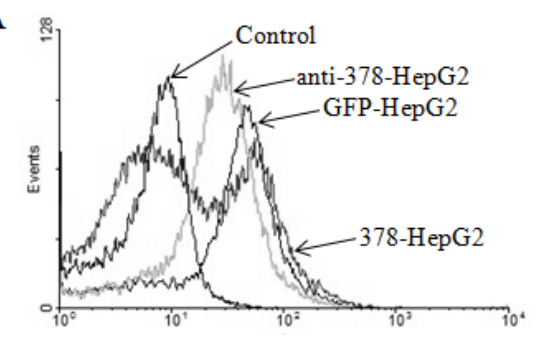

C 378 GFP anti-378

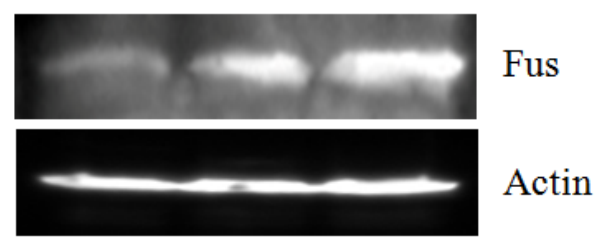

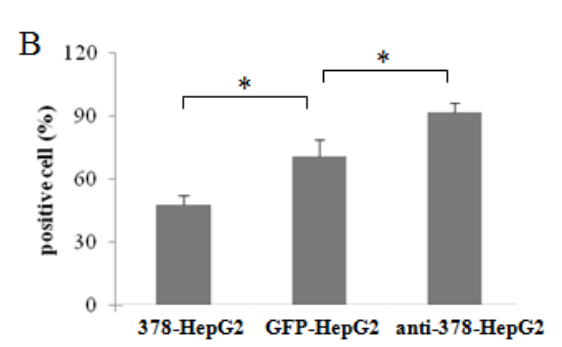

$\mathrm{D}$

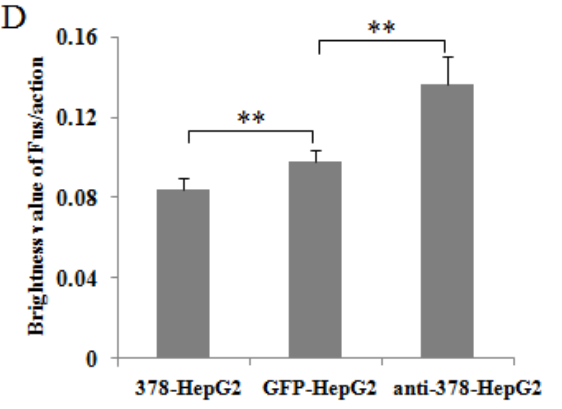

Fig. 4. Down-regulation of Fus by miR-378. (A) miR-378-HepG2, GFP-HepG2 or anti-378-HepG2 cells were analyzed for Fus expression by flow cytometry. (B) Statistical analysis for A. (C) Cell lysates from miR-378HepG2, GFP-HepG2 and anti-378-HepG2 cells were analyzed by western blot for Fus expression. Fus expression was repressed by miR-378 transfection. Blotting for actin confirmed equal loading. (D) Statistical analysis for $\mathrm{C} .{ }^{* *}, p<0.01$.

transfected cells (Fig. 3A). This result indicated that miR-378 expression could enhance liver cell invasion.

\section{miR-378 enhances liver cancer metastasis}

To confirm the function of miR-378, aliquots of the two stably transfected cell lines were intraperitoneally injected into BALB/c nude mice. The mice were sacrificed and examined four weeks after the injection. Notably, four mice in the miR-378 group developed large abdomens because the mice in this group generated more ascitic fluid than those in the GFPHepG2 group (Fig. 3B and C), and one of these mice died due to serious disease. Typical metastatic lesions in the liver were observed (Fig. 3D) in the miR-378 group. Nodules were detected, indicating the metastasis of the tumor cells to the liver. DNA was isolated from liver tissues and subjected to PCR to amplify the CMV promoter, which was used to drive miR-378 expression in the construct, to indicate the metastasis of the cancer cells. miR-378 expression significantly increased the CMV promoter levels (Fig. 3E).

\section{Repression of Fus expression by miR-378 transfection}

Fus is reported to function as a tumor suppressor. Fus is a reported target of miR378[26]; thus, we examined Fus expression in miR-378-, anti-miR-378- or GFP-transfected cells by flow cytometry and western blotting. The flow cytometry results showed that Fus expression decreased in miR-378-HepG2 cells and increased in anti-378-HepG2 cells (Fig. 4A and B). These results were confirmed by the western blot analysis (Fig. 4C and D), suggesting that miR-378 inhibited Fus expression.

\section{Discussion}

Previous studies have shown that miR-378 is expressed in several cancer cell lines [31], and the biological importance of miR-378 has gradually been elucidated. miR-378 is 
involved in promoting cell survival, tumor growth, and angiogenesis in glioblastoma cells [26], in regulating osteoblast differentiation [28] and in tumor cell self-renewal and chemoresistance [27]. However, the function of miR-378 in liver cancer cells has not been reported thus far. Thus, we examined the effect of miR-378 expression on liver cancer.

In this study, we observed that liver cancer cells (HepG2) transfected with miR-378 acquired metastatic properties. Wound healing experiments and invasion assays were performed. The results showed that the miR-378-transfected cells promoted HepG2 cell migration and invasion more than the GFP-transfected cells.

Then, we tested the role of miR-378 in metastasis by introducing the transfected cells into four-week-old BALB/c nude mice via intraperitoneal injection. In the miR-378 group, one mouse died due to serious disease, and four of the mice developed large abdomens because the mice in this group generated more ascitic fluid than the mice in the GFP-HepG2 group. Typical metastatic lesions were found in the livers of the mice in the miR-378 group, suggesting that miR-378 promoted liver cell metastasis. As to the possibility of endogenous miR-378 expression, the CMV promoter is not endogenously expressed in mammalian cells, and thus its expression reflects the presence of transfected cells. We detected CMV promoter levels in mouse livers to reflect cancer cell metastasis. The result showed that CMV promoter expression increased in the liver tissues of the miR-378 group, suggesting that miR-378 promoted liver cell metastasis.

All of these results indicated that miR-378 promoted the metastasis of the liver cancer cells. We previously reported that miR-378 promotes cell survival, tumor growth and angiogenesis in a human primary glioblastoma cell line [26]; however, the role of miR-378 in migration and metastasis in liver cancer has not been previously reported. In this paper, we revealed the function of miR-378 in liver cancer metastasis. Our study demonstrated that miR-378 enhanced liver cancer cell proliferation, migration, invasion and metastasis. In addition to these functions, miR-378 also participates in cellular self-renewal [27] and osteoblast differentiation regulation [28]. Thus, considering its biological characteristics, miR-378 is categorized as an oncogene. As we know, most miRNAs play roles as tumor suppressors, and only a few, including miR-106a [32], miR-19a [33] and several others, are up-regulated in various cancers. This finding shows that miR-378 down-regulation may be a useful therapeutic strategy for inhibiting liver cancer growth and metastasis.

Then, we searched for the target protein of miR-378. Our previous results have demonstrated that miR-378 functions as an oncogene by enhancing tumor cell survival and tumor growth. Additionally, miR-378 acts on the tumor suppressor Fus-1 [26]. We detected Fus expression in miR-378-, anti-miR-378- and GFP-transfected cells by flow cytometry and by western blotting. The results showed that lower Fus expression was found in miR-378HepG2 cells and that higher Fus expression was found in anti-378-HepG2. These findings suggested that miR-378 might promote liver cancer metastasis by down-regulating Fus expression. Other tumor suppressors may also be involved in miR-378 functions because miR-378 may target multiple mRNAs. These findings shed light on the possibility of targeting oncogenic miRNAs as a direction for gene therapy. Thus far, Charles Lu [34] has performed a systemic gene therapy phase I clinical trial with targeted Fus:cholesterol nanoparticles encapsulating a Fus expression plasmid, which is used in recurrent and/or metastatic lung cancer patients. It specifically altered Fus-regulated pathways and acquired anti-tumor effects. Soon, targeting oncogenic miRNAs for gene therapy will also be developed.

We have demonstrated that miR-378 can facilitate tumor cell metastasis and is highly expressed in border tissues compared with tumor tissues, promoting migration in miR378-transfected cells and contributing to the metastasis of cancer cells in a mouse model. Additionally, this metastatic activity appears to be the consequence of the down-regulation of Fus expression. Our study provides an analysis of miR-378 functions for basic research and clinical applications. 
Ma et al.: MiR-378 Promotes Migration

\section{Acknowledgements}

This study was supported by National Natural Science foundation of China (81172592, 81270630), Science and Technology Special Project in Clinical Medicine of Jiangsu Province (BL2012056) and 333 Project of Jiangsu Province (BRA2011085).

\section{Disclosure Statement}

The authors declare no conflict of interest.

\section{Reference}

Lim LP, Glasner ME, Yekta S, Burge CB, Bartel DP: Vertebrate microRNA genes. Science 2003;299:1540. Hutvagner G, Zamore PD: A microRNA in a multiple-turnover RNAi enzyme complex. Science 2002;297:2056-2060. Bartel DP: MicroRNAs: genomics, biogenesis, mechanism, and function. Cell 2004;116:281-297. Ambros V: The functions of animal microRNAs. Nature 2004;431:350-355. Tzur G, Levy A, Meiri E, Barad O, Spector Y, Bentwich Z, Mizrahi L, Katzenellenbogen M, Ben-Shushan E, Reubinoff BE, Galun E: MicroRNA expression patterns and function in endodermal differentiation of human embryonic stem cells. PLoS One 2008;3:e3726.

6 Thompson BJ, Cohen SM: The Hippo pathway regulates the bantam microRNA to control cell proliferation and apoptosis in Drosophila. Cell 2006;126:767-774.

7 Laneve P, Di Marcotullio L, Gioia U, Fiori ME, Ferretti E, Gulino A, Bozzoni I, Caffarelli E: The interplay between microRNAs and the neurotrophin receptor tropomyosin-related kinase $\mathrm{C}$ controls proliferation of human neuroblastoma cells. Proc Natl Acad Sci U S A 2007;104:7957-7962.

8 Gao S, Wassler M, Zhang L, Li Y, Wang J, Zhang Y, Shelat H, Williams J, Geng YJ: MicroRNA-133a regulates insulin-like growth factor-1 receptor expression and vascular smooth muscle cell proliferation in murine atherosclerosis. Atherosclerosis 2014;232:171-179.

-9 Hatfield SD, Shcherbata HR, Fischer KA, Nakahara K, Carthew RW, Ruohola-Baker H: Stem cell division is regulated by the microRNA pathway. Nature 2005;435:974-978.

10 Poy MN, Eliasson L, Krutzfeldt J, Kuwajima S, Ma X, Macdonald PE, Pfeffer S, Tuschl T, Rajewsky N, Rorsman P, Stoffel M: A pancreatic islet-specific microRNA regulates insulin secretion. Nature 2004;432:226-230.

11 Wu H, Neilson JR, Kumar P, Manocha M, Shankar P, Sharp PA, Manjunath N: miRNA profiling of naive, effector and memory CD8 T cells. PLoS One 2007;2:e1020.

12 Jopling CL, Yi M, Lancaster AM, Lemon SM, Sarnow P: Modulation of hepatitis C virus RNA abundance by a liver-specific MicroRNA. Science 2005;309:1577-1581.

13 Deng ZQ, Yin JY, Tang Q Liu FQ, Qian J, Lin J, Shao R, Zhang M, He L: Over-expression of miR-98 in FFPE tissues might serve as a valuable source for biomarker discovery in breast cancer patients. Int J Clin Exp Pathol 2014;7:1166-1171.

14 Deng ZQ, Qian J, Liu FQ, Lin J, Shao R, Yin JY, Tang Q Zhang M, He L: Expression level of miR-93 in formalinfixed paraffin-embedded tissues of breast cancer patients. Genet Test Mol Biomarkers 2014;18:366-370.

15 Luo L, Ye G, Nadeem L, Fu G, Yang BB, Honarparvar E, Dunk C, Lye S, Peng C: MicroRNA-378a-5p promotes trophoblast cell survival, migration and invasion by targeting Nodal. J Cell Sci 2012;125:3124-3132.

16 Zhang GJ, Zhou H, Xiao HX, Li Y, Zhou T: MiR-378 is an independent prognostic factor and inhibits cell growth and invasion in colorectal cancer. BMC Cancer 2014;14:109.

17 Wang CH, Lee DY, Deng Z, Jeyapalan Z, Lee SC, Kahai S, Lu WY, Zhang Y, Yang BB: MicroRNA miR-328 regulates zonation morphogenesis by targeting CD44 expression. PLoS One 2008;3:e2420.

18 Shan SW, Lee DY, Deng Z, Shatseva T, Jeyapalan Z, Du WW, Zhang Y, Xuan JW, Yee SP, Siragam V, Yang BB: MicroRNA MiR-17 retards tissue growth and represses fibronectin expression. Nat Cell Biol 2009;11:10311038.

19 Fang L, Deng Z, Shatseva T, Yang J, Peng C, Du WW, Yee AJ, Ang LC, He C, Shan SW, Yang BB: MicroRNA miR93 promotes tumor growth and angiogenesis by targeting integrin-beta8. Oncogene 2011;30:806-821. 


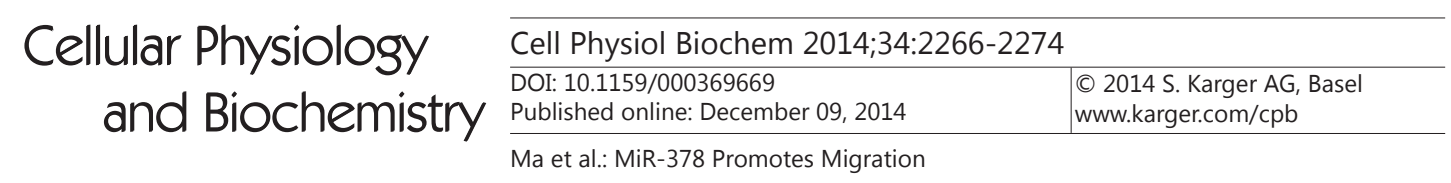

20 Zampetaki A, Mayr M: MicroRNAs in vascular and metabolic disease. Circ Res 2012;110:508-522.

21 Ma L, Teruya-Feldstein J, Weinberg RA: Tumour invasion and metastasis initiated by microRNA-10b in breast cancer. Nature 2007;449:682-688.

22 Yang W, Lee DY, Ben-David Y: The roles of microRNAs in tumorigenesis and angiogenesis. Int J Physiol Pathophysiol Pharmacol 2011;3:140-155.

23 Hammond SM: MicroRNAs as oncogenes. Curr Opin Genet Dev 2006;16:4-9.

-24 Calin GA, Croce CM: MicroRNA signatures in human cancers. Nat Rev Cancer 2006;6:857-866.

25 Wu QP, Xie YZ, Deng Z, Li XM, Yang W, Jiao CW, Fang L, Li SZ, Pan HH, Yee AJ, Lee DY, Li C, Zhang Z, Guo J, Yang BB: Ergosterol peroxide isolated from Ganoderma lucidum abolishes microRNA miR-378-mediated tumor cells on chemoresistance. PLoS One 2012;7:e44579.

-26 Lee DY, Deng Z, Wang CH, Yang BB: MicroRNA-378 promotes cell survival, tumor growth, and angiogenesis by targeting SuFu and Fus-1 expression. Proc Natl Acad Sci U S A 2007;104:20350-20355.

-27 Deng Z, Du WW, Fang L, Shan SW, Qian J, Lin J, Qian W, Ma J, Rutnam ZJ, Yang BB: The intermediate filament vimentin mediates microRNA miR-378 function in cellular self-renewal by regulating the expression of the Sox2 transcription factor. J Biol Chem 2013;288:319-331.

28 Kahai S, Lee SC, Lee DY, Yang J, Li M, Wang CH, Jiang Z, Zhang Y, Peng C, Yang BB: MicroRNA miR-378 regulates nephronectin expression modulating osteoblast differentiation by targeting GalNT-7. PLoS One 2009;4:e7535.

-29 Uzhachenko R, Ivanov SV, Yarbrough WG, Shanker A, Medzhitov R, Ivanova AV: Fus1/Tusc2 is a novel regulator of mitochondrial calcium handling, Ca2+-coupled mitochondrial processes, and Ca2+-dependent NFAT and NF-kappaB pathways in CD4+ T cells. Antioxid Redox Signal 2014;20:1533-1547.

-30 Fang L, Du WW, Yang W, Rutnam ZJ, Peng C, Li H, O'Malley YQ Askeland RW, Sugg S, Liu M, Mehta T, Deng Z, Yang BB: MiR-93 enhances angiogenesis and metastasis by targeting LATS2. Cell Cycle 2012;11:4352-4365.

-31 Jiang J, Lee EJ, Gusev Y, Schmittgen TD: Real-time expression profiling of microRNA precursors in human cancer cell lines. Nucleic Acids Res 2005;33:5394-5403.

32 Li P, Xu Q, Zhang D, Li X, Han L, Lei J, Duan W, Ma Q, Wu Z, Wang Z: Upregulated miR-106a plays an oncogenic role in pancreatic cancer. FEBS Lett 2014;588:705-712.

33 Wu TY, Zhang TH, Qu LM, Feng JP, Tian LL, Zhang BH, Li DD, Sun YN, Liu M: MiR-19a is correlated with prognosis and apoptosis of laryngeal squamous cell carcinoma by regulating TIMP-2 expression. Int J Clin Exp Pathol 2013;7:56-63.

-34 Lu C, Stewart DJ, Lee JJ, Ji L, Ramesh R, Jayachandran G, Nunez MI, Wistuba II, Erasmus JJ, Hicks ME, Grimm EA, Reuben JM, Baladandayuthapani V, Templeton NS, McMannis JD, Roth JA: Phase I clinical trial of systemically administered TUSC2(FUS1)-nanoparticles mediating functional gene transfer in humans. PLoS One 2012;7:e34833. 